\title{
РОЛЬ ТЕХНОГЕННЫХ ФАКТОРОВ В ФОРМИРОВАНИИ ГИДРОХИМИЧЕСКОГО РЕЖИМА РЕК БАССЕЙНА р. ВОЛИМ
}

\author{
С.А Мирошниченко \\ Горный институт УрО РАН, г. Пермь.
}

\begin{abstract}
Аннотация: В работе дан анализ основных техногенных факторов влияющих на изменение гидрохимического режима малого водотока реки Волим, правого притока р.Яйва в бассейне которого расположены предприятия калийной и нефтедобывающей промышленности. Предложены природоохранные мероприятия по сокращению техногенной нагрузки на водные объекты.
\end{abstract}

Ключевые слова: техногенное загрязнение, малый водоток, река Волим.

Гидрохимический режим малого водотока определяется достаточно сложным сочетанием естественных и антропогенных факторов. При этом в зависимости от почвенногеохимических условий водосборной площади, условий формирования химического стока, масштабов техногенного загрязнения он может очень существенно различаться и варьировать не только внутри года в весьма широком диапазоне, но и по его длине. Особенно это касается малых водотоков, расположенных в зоне деятельности крупных горнодобывающих предприятий, с высокой концентрацией промышленного производства, как в Соликамско-Березниковском промузле. Особенности формирования техногенных воздействий на водные объекты Соликамско-Березниковского промузла были рассмотрены в работах $[1,2]$. Одним из таких водных объектов является р. Волим.

Река Волим является правым притоком р. Яйвы и впадает в неё на 7,8 км от устья.

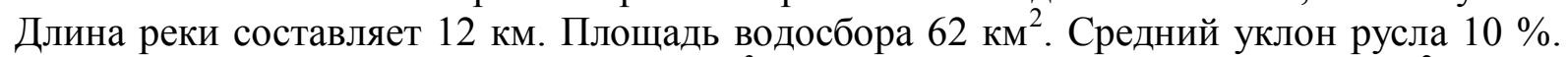
Среднемноголетний расход воды $-0,59 \mathrm{~m}^{3} / \mathrm{c}$. Густота речной сети 0.8-1.0 км/км². Код и наименование водохозяйственного участка -10.01.01.009-р. Кама (Камское водохранилище) - ниже устья р. Ленва- выше г. Перми (г/п Галкино Городище). Ширина водоохранной зоны водного объекта в соответствии с [3] -100 м, прибрежно-защитной полосы -50м.

В административном плане река полностью протекает по территории г. Березники. Река берет свое начало из родников. Река течёт на юго-запад, затем поворачивает на северо-запад. Русло извилистое. Притоки - Чёрная (правый); Малый Падун, Большой Падун (левые). Впадает в р. Яйву у деревни Володин Камень. Подпор Камского водохранилища, в которое впадает р. Яйва распространяется и на р. Волим, на последних километрах течения р. Волим образует залив.

По данным Пермского ЦГМС - филиала ФГБУ «Уральское УГМС» на водных объектах территории исследований (бассейн р. Волим) регулярные наблюдения не производились. В соответствии с критериями СП 11-103-97 [4] реки исследуемой территории в гидрологическом отношении не изучены. По гидрологическому районированию [5], p. Волим и ее притоки по особенностям внутригодового распределения стока относится к району 1. Этот район включает бассейны левых притоков р. Камы, стекающих со склонов Северного Урала в том числе и р.Яйва. Режим этих рек характеризуется относительно выровненным распределением стока внутри года. Весенний сток средних рек составляет 55 - $65 \%$, меженный сток $35-45 \%$, а зимний $7-10 \%$ годового. Реки рассматриваемой территории относятся к типу рек с четко выраженным весенним половодьем, летне-осенними дождевыми паводками и длительной устойчивой зимней меженью. Для водных объектов рассматриваемого региона при естественных условий формирования гидрохимического режима характерен гидрокарбонатно-кальциевый состав воды. 
Современное состояние условий формирования гидрохимического режима р. Волим в среднем и устьевом участке водного объекта определяется в основном техногенными факторами, накладывающимися на естественные зональные условия.

Бассейн р.Волим -это территория комплексного использования, где под соляной толщей из калийных и магниевых солей расположено разрабатываемое нефтяное месторождение. Калийная промышленность в среднем течении р.Волим представлена двумя крупными предприятия БКПРУ-3 ПАО «Уралкалий» и ООО "ЕвроХим Усольский калийный комбинат" (ООО «ЕвроХим-УКК»). БКПРУ-3 был введен в эксплуатацию в 1973 году. В результате аварийной ситуации его рудник был затоплен в 1986 году. В настоящее время БКПРУ-3 выпускает мелкозернистый и гранулированный хлористый калий. Метод производства - флотационное обогащение сильвинитовой руды. Проектная мощность производства мелкозернистого хлористого калия - 2,080 млн. тонн в год, гранулированного - 1,8 млн. тонн в год. ООО «ЕвроХим-УКК» расположено на территории Палашерского и Балахонцевского участков занимается производством хлористого калия. Предприятие начало выпуск продукции с 2018 года. Основные структурные подразделения комбината; горнодобывающий и обогатительный комплексы. За 2018 год на комбинате было добыто 1,38 млн т калийных руд. С освоением проектной мощности совокупная производительность первой очереди составит 2,3 млн т хлористого калия в год. Кроме предприятий калийной промышленности в бассейне р. Волим ООО «ЛУКОЙЛ-ПЕРМЬ» ведет разработку Архангельского месторождения нефти запасы, которого по категории $\mathrm{C} 1+\mathrm{C} 2$ составляют порядка 7 млн тонн (объекты нефтедобычи и транспортировки нефти сосредоточены в бассейне р.Б.Падун-левый приток р. Волим). В настоящее время, к числу наиболее опасных загрязняющих веществ попадающих в поверхностные водные объекты относятся нефтяные углеводороды, источниками которых в основном являются аварийные разливы при добыче и транспортировке нефти. Аварии на нефтепроводах в местах водных переходов приводят к быстрому распространению по течению водотока нефтесодержащей жидкости и значительной аккумуляции органических соединений в придонном слое. Необходимо отметить, что даже незначительное нефтяное загрязнение вызывает нарушение многих естественных процессов и взаимосвязей в водной экосистеме, существенно изменяя условия обитания не только водной, но и прибрежной флоры и фауны.

Если специфика воздействия объектов нефтедобычи на природную среду связана с преимущественно неорганизованным распределенным (подземным и поверхностным стоком) поступлением загрязняющих веществ с территории разрабатываемых нефтяных месторождений и высокой вероятностью аварийных ситуаций в различных звеньях технологической цепи, то производство калийных удобрений неизбежно связано с накоплением большого количества солеотходов, образующихся в процессе извлечения хлористого калия из сильвинитовой руды. Образующиеся рассолы поступают в наземные емкости-накопители как в жидком (глинисто-солевые шламы), так и в твердом (галитовые отходы) видах. По химическому составу они на 88- 96 \% состоят из хлористого натрия; остальная часть содержит в небольших количествах КС1. После переработки руды, солеотходы складируются вблизи предприятий, образуя значительные накопления в виде шламохранилищ и солеотвалов. Галитовые отходы, складируемые в отвалы, составляют основную массу солеотходов. Рассолы, накапливающиеся на солеотвале, можно разделить на несколько видов:

- первичные (технологические или отжимные) рассолы;

- вторичные (избыточные) рассолы, образующиеся под воздействием климатических факторов;

- рассолы испарения и конденсации. 
Образующиеся на солеотвале, в первую очередь избыточные рассолы, являются потенциальными источниками засоления подземных вод и поверхностных водотоков. Для защиты приповерхностной гидросферы от засоления на предприятиях используют противофильтрационный экран. На правом притоке р. Волим - p. Черная расположен рассолосборник и солеотвал БКПРУ-3. Общая площадь, занимаемая солеотвалом БКПРУ3 ПАО "Уралкалий" составляет 145 га, на которой складировано порядка 100 млн.т. галитовых отходов. Декларируемых точечных источников сброса в р.Черная БКПРУ-3 не имеет. Шламохранилише и солеотвал ООО «ЕвроХим-УКК» расположены в бассейне р.М.Падун (левый приток р.Волим). Закладка в них отходов и рассолов была начата только с 2018 года.

Район расположения ООО «ЕвроХим-УКК» характеризуется сложной водноэкологической обстановкой. Особенностью гидрохимического режима р. Волим по результатам наблюдений ООО «ЕвроХим-УКК» за 2011-2017 годы (до начало работы предприятия), является, что после впадения на 7 км от устья в нее вод р. Черная отмечается не характерный для природных условий формирования тип вод: хлориднонатриевый с минерализацией воды до 13 г/л, с содержанием хлоридов в воде до 8 г/л, калия+натрия до 4 г/л, сульфатов, кальция и магния до 0,6 г/л. На р. Черная содержание всех рассматриваемых макрокомпонентов солевого состава, являющимися маркерными показателями для калийной промышленности, значительно превышает установленные нормативов качества воды для рыбохозяйственных водных объектов, так для сухого остатка в 45 раз, хлоридов в 86 раз. Приток в р. Волим сильно минерализованных вод с бассейна р. Черная вод дает заметное увеличение минерализации речной воды, которое в дальнейшем прослеживается по всей длине рассматриваемого водотока. Воды р. Волим в среднем и нижнем течении после впадения р. Черная соответствуют категории воды солоноватые хлоридного калиево-натриевого состава. В анионном составе вод р.Волим доминируют ионы хлора, в катионном составе преобладают ионы натрия и калия, что не характерно для естественного гидрохимического облика поверхностных вод. К основным причинам, характерным для всей калийной промышленности Соликамского-Березниковского промузла, приводящим к интенсивному загрязнению малых водотоков, можно отнести:

- особенность химического состава добываемых руд и прежде всего их высокой степени растворимостью;

- климатическими условиями территории (гумидный тип климата);

- размещения значительного количества отходов производств, которые складируются в солеотвалы и шламохранилища.

Содержание в воде р. Волим нефтепродуктов (основного индикатора загрязнения от нефтедобывающей промышленности) - в норме, что свидетельствует об отсутствии на р.Б. Падун крупных аварий с розливом нефти. Таким образом, на основании анализа результатов ведомственной сети наблюдений за р. Волим и ее притоками можно сделать следующие выводы:

Результаты режимных наблюдений отражают многофакторность формирования гидрохимического режима в зоне активного техногенеза.

По результатам наблюдений за 2011-2017гг на формирование водного и гидрохимического режима рек Волим и Черная опосредовано оказывает влияние производственная деятельность крупного калийного предприятия.

В течение года наибольшие концентрации макрокомпонентов солевого состава р.Волим приходятся на период зимней межени, когда питание водотоков полностью определяется подземным стоком. Благодаря перемешиванию с водами р.Яйва в период весеннего паводка и в условиях подпора содержание макрокомпонентов солевого состава в р.Волим на устьевом участке снижается. 
По данным Росгидромета вода в Камском водохранилище в створе г. Березники, 10 км ниже города (п.Орел) по компонентам характерным для предприятий калийной промышленности укладывается в общефедеральные нормативы качества воды разработанных для рыбохозяйственных водных объектов (ПДК р/х).

Основная масса выноса макрокомпонентов солевого состава по фактическим данным за период 2011-2017 гг. приходится на р. Черная (по хлоридам, калию, натрию, сульфату, сухому остатку более $90 \%$, по кальцию и магнию более $60 \%$ ). Реки Малый и Большой Падун по данным показателям дают прирост не более $2 \%$, доля р.Волим выше устья р.Черная по калию, натрию, хлоридам, сульфатам менее 7\%. Фактически естественный сток реки Волим не справляется с поступившим через р.Черная загрязнением. Улучшение экологической ситуации на р. Волим возможно только после прекращения интенсивного загрязнения засоленными водами поступающих с бассейна p.Черной. Данные выводы были подтверждены результатами в ходе проведенного маршрутного наблюдения сотрудниками лаборатории проблем гидрологии суши «ГИ УрО РАН» в 2019 году. В ходе которого в местах интенсивного водопользования на р.Волим и ее притоках были проведены гидрологических наблюдений с определением расхода воды и отбора проб с определением в воде, приоритетных для калийной промышленности показателей (хлориды, сульфаты, калий, магний, натрий, калий, сухой остаток). Результаты наблюдений за качеством поверхностных вод по длине р.Волим представлены на рисунке (рис. 1).

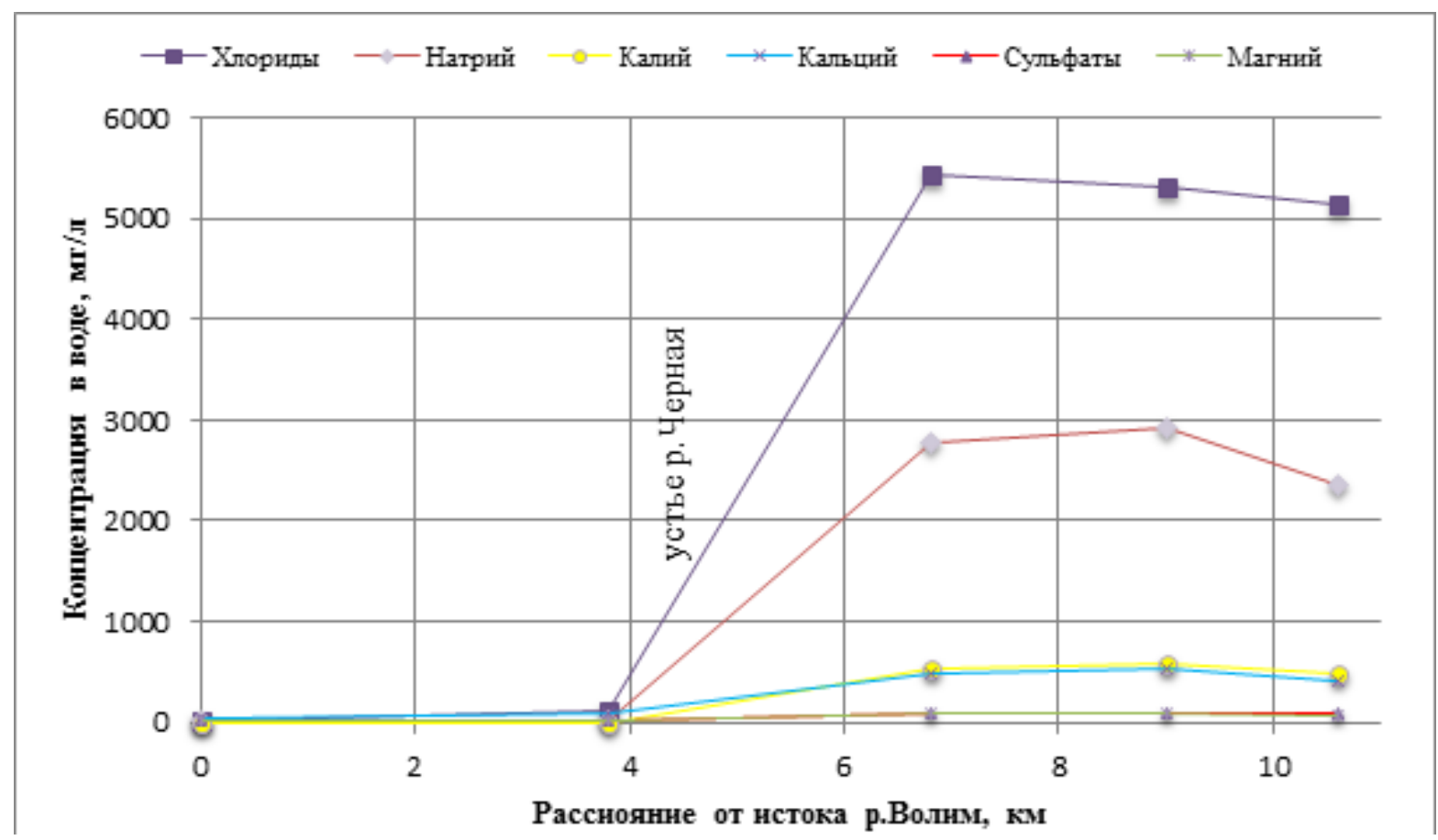

Рис. 1. Изменение по длине р.Волим концентрации в воде основных макрокомпанентов солевого состава

Так же в ходе маршрутного обследования было описано экологическое состояние прибрежной защитной полосы и водоохранной зоны малых водотоков.

Малые водотоки наиболее сильно подвержены загрязнению, так как при низких показателях природной составляющей водного стока, особенно в период зимней межени, даже незначительное поступление загрязненных вод дает заметное увеличение минерализации речной воды, которое прослеживается в дальнейшем по всей длине рассматриваемого водотока. Одним из вариантов решения данной проблемы, может стать разработка проекта перехвата засоленных вод в долине малых водотоков и их отведения че- 
рез рассеивающий выпуск в крупный водный объект (Камское водохранилище) способный справится с учетом разбавления с загрязнением или закачкой образующихся избыточных рассолов в достаточно глубокие подземные горизонты. С точки зрения рационального использования водных ресурсов, наиболее эффективным вариантом стало бы замещение используемых в нефтедобывающей промышленности поверхностных вод для поддержания пластового давления на образующиеся на предприятиях калийной промышленности избыточные рассолы. Данные природоохранные мероприятия являются достаточно дорогостоящими, но способные значительно снизить оказываемую техногенную нагрузку на малые водотоки.

Необходимо отметить, что отмечаемое загрязнение р.Черная сложилось еще в 70 годы прошлого века. ПАО «Уралкалий» получил в наследие еще от советского периода сложившуюся экологическую проблему, связанную с выбором технологии добычи и переработки полезных ископаемых и складированием образующихся отходов.

Зачастую утвержденная схема водоотведения промышленного предприятия, разработанная еще в советское время предусматривала отведение стоков через открытое русло малых водных объектов в крупный водоток-приемник на ассимилирующую способность которого был рассчитан данный объем транспортируемых промышленных стоков. При этом малые водотоки -приемники за десятки лет такого использования фактически перестали существовать, как природный водный объект, а превратились в технический канал для отведения промышленных загрязненных стоков. При этом объем транспортируемых стоков во много раз превышает норму естественного стока поступающей в русло реки с водосборной территории малого водотока. На сегодняшний день, не смотря на свой фактический статус технического канала, все водные объекты в априори отнесены к рыбохозяйственным водным объектам, не смотря на то, что их исток может начинаться в месте сброса сточных вод. Промышленные предприятия оказались заложниками разработанной и согласованной на то, время схемы водоотведения. В связи с этим представляется более оправданной двухступенчатая схема реализации водоохранных мероприятий. На первой стадии решается задача безусловного достижения нормативного качества воды в водных объектах, представляющая собой реальную потребительскую ценность (для целей рыбного хозяйства, культурно-бытового и питьевого водопользования). Затем на второй стадии решается задача достижения нормативных требований и качества воды на сами отводимые сточные воды. В настоящее время имеются достаточно серьезные проработки по методологии построения региональных нормативов качества воды поверхностных водных объектов, на основе анализа их гидрохимического режима. Накоплен достаточно большой опыт материалов натурных наблюдений, позволяющий проводить достаточно надежные статистические оценки. Однако остается совершенно открытым вопрос о процедуре согласования и утверждения данных нормативов. В то же время для практической реализации данный методический документ имеет решающее значение.

Формальное отнесение всех водных объектов к рыбохозяйственным напрямую противоречит Постановлению Правительства РФ от 28 февраля 2019 года № 206, где четко указано, что отнесение к водным объектам рыбохозяйственного значения осуществляется при наличии одного из следующих критериев:

«а) водный объект или часть водного объекта представляет собой место обитания, размножения, зимовки, нагула, путей миграций водных биологических ресурсов (при наличии одного из показателей);

б) водный объект или часть водного объекта используется для добычи (вылова) водных биологических ресурсов;

в) водный объект или часть водного объекта используется для сохранения и искусственного воспроизводства водных биологических ресурсов.» 
Сутью данного правого документа является попытка в будущем перехода, там где это целесообразно при регламентации техногенных нагрузок и оценки качества поверхностных вод, от рыбохозяйственных к более объективным для данного случая санитарно-гигиеническим нормативам (ПДК), ориентированных на использование вод сугубо для нужд человека. Которые в большинстве случаев являются менее жесткими чем соответствующие ПДК для водных объектов рыбохозяйственного значения.

Работа выполнена при поддержке гранта РФФИ (проект №17-05-00842A «Научное обоснование и разработка методологии оценки экологических рисков при загрязнении поверхностных водных объектов химическими вещеествами»)

\title{
БИБЛИОГРАФИЧЕСКИЙ СПИСОК
}

1. Лепихин А.П., Мирошниченко С.А. Особенности формирования техногенного воздействия в Соликамско-Березниковском промузле // Водное хозяйство России: Проблемы, технологии, управление. 2003. - Т. 5, № 5. - С. 449-466.

2. Лепихин А.П., Мирошниченко С.А Техногенное воздействие Соликамско-Березниковского промузла на поверхностные водные объекты / А.П. Лепихин, С.А. Мирошнеченко // Горн. журн. - 2008. - № 10. - С. 92-96.

3. Водный кодекс Российской Федерации: Ф3-74, (с изменениями на 2 августа 2019 года. Редакция, действ. С 1 янв. 2020 г. - Текст электронный // Консорциум КОДЕКС. Электронный фонд правовой и нормативно-технической документации: офиц. сайт. - URL: http://docs.cntd.ru/document/901982862. (Дата обращений 23.03.2020)

4. СП 11-103-97. Инженерно-гидрометеорологические изыскания для строительства: утв. 10.07.1997. M., 2004. -34 c.

5. Ресурсы поверхностных вод СССР: Основные гидрологические характеристики. Т. 11. Средней Урал и Приуралье. Вып 1. Кама / под ред. И.С. Шахова. - Л.: Гидрометеоиздат, 1967. - 535 с.

УДК 564.171

DOI:10.7242/echo.2020.1.5

\section{ИСКОПАЕМЫЕ ДВУСТВОРЧАТЫЕ МОЛЛЮСКИ ИЗ ОТЛОЖЕНИЙ СОЛИКАМСКОЙ ВПАДИНЫ}

\author{
Т.В. Фадеева \\ Горный институт УрО РАН, Пермь, Россия
}

\begin{abstract}
Аннотация. В статье приведены результаты предварительного морфологического исследования ископаемых двустворчатых моллюсков из отложений участков Соликамской впадины. Выявлены три морфотипа, установлены наиболее значимые морфометрические признаки и вероятная видовая принадлежность ископаемых раковин.

Ключевые слова: двустворчатые моллюски, Соликамский горизонт, Верхнекамское месторождение солей.

Сведения о двустворчатых моллюсках из пермских континентальных отложений Восточно-европейской платформы довольно скудны и противоречивы, прежде всего это связано с разными точками зрения исследователей на таксономическое разнообразие и стратиграфическое распространение этих животных (Silantiev et al., 2018). O.А. Бетехтина (1966) отмечала наличие специфических особенностей ископаемых двустворок, в силу которых они являются чрезвычайно сложными для диагностики и использования в стратиграфии. Постмортальные деформационные изменения, возможное наличие экологических морф (по аналогии с унионидами), онтогенетические различия могут привести к ложным видовым идентификациям при использовании только морфометрических признаков ископаемых раковин.
\end{abstract}

